will guarantee the patient from a relapse of the disease in certain constitutions. It will be no answer to the plan $I$ havè recommended in the course of this and former papers to say, that had I used the various preparation, relapses would not have occurred. I could give extracts from nearly all writers to show that they do occur; and I have elsewhere shown that a relapse is a natural consequence of syt lis in certain constitutions, do what you will in our northern climates; but I can easily understand, and have occasional evidence of, the effect of climate, food, and temperature, in producing secondary symptoms; and because relapses are not frequent in the south, it does not follow they are present in the north, because there we give mercury. The day is, however, passed for the discussion of the non.mercurial doctrines: the surgeon now discusses how we may give the mineral with the greatest economy of the constitutional powers, and yet with the most probable means of guaranteeing. the system from relapse. It is upon these two points that I have wished particularly to dwell, believing them to be of paramount importance; and if, in doing so, I have fatigued the attention of my readers, I must plead the importance of the subject, which has not lately been brought before the profession.

Queen-Anne-street, Cavendish-square.

A FEW OBSERVATIONS ON THE USE OF PRO FESSOR SEUTIN'S STARCH BANDAGE IN THE TREATMENT OF FRACTURES.

By Alfred Markwick, Esq., Surgeon, London.

IN the treatment of fractures, any apparatus capable of fulfilling the chief indication-namely, that of maintaining the extremities of the fractured bones in exact apposition, and which, at the same time, permits of progression-must undoubtedly be a very valuable one to the surgeon. Numerous apparatus have been invented for this purpose, since the time of Hippocrates; the principal ones now had recourse to are, the common apparatus, with splints, Dessault's long splint, with Boyer's modification of it, for fractures of the thigh; the double-inclined planes of Mac Intyre, Liston, and Amesbury; Greenhow's apparatus; the fracture-box; the appareils inamovibles of Larrey, and Fmile Lacroix, the former consisting of -1stly, a linen cloth several times double; 2 ndly, two cylinders or junks, formed of straw bound tightly together with twine, each an inch and a half in diameter, and rather shorter than the cloth; 3rdly, one or two bags or cushions, stuffed with chaff, of sufficient thickness, and of the same length as the junks; 4thly, a conical pad, stuffed with torv, six inches long, three wide, and two thick at its base; 5thly, three six-tailed compresses; 6thly, a long compress, called the stirrup; 7thly, the "tibiale," a large piece of linen cut to the shape of the apparatus; 8 thly, ligatures five or six in number; 9 thly, the resolvent liquid, a mixture of camphorated spirit, Goulard water, and white of egg, beaten together in water; and the latter, which is frequently employed by Dieffenbach, of a solid case of plaster of Paris, procured by pouring into a convenient sized wooden box, containing the fractured limb covered with oil or cerate, a sufficient quantity of the semifluid gypsum: the appareil hyponarthreciouce, or " a suspension," proposed by Sauter, of Constance, in 1812, and adopted, with certain modifications, by Nayor, of Lausanne, and Chelius, of Heidelberg. It consists of a flat piece of board, a chaff cushion, and ligatures for fixing the limb; the whole is suspended by attaching a cord, passed through a hole in each corner of the board, to a pulley, fixed either to the cciling, or the top of the bed: the moulding tablets of Mr. Smee, prepared by copiously brushing over one side of a piece of coarse sheeting with a thick solution of gum, and afterwards covering it "with a composition made by rubbing whiting with mucilage, continually adding the powder, until the whole" is " of the consistence of a thick paste; a second piece of sheeting" is then "rubbed over on one side with the solution of gum, and the moistened side applied upon the composition with which the piece of sheeting" has "been covered;" the apparatus invented by Johert, of the Môpital St. Louis, Paris, which consists of a leather sock or bracelet fastened to the foot of the bed, for making extension, a long cloth folded and passed over the opposite side of the body, and fixed to the head of the bed for producing counter-extension, and another, if required, placed across the limb, for counteracting the action of the muscles on the upper extremity of the fractured bone; and lastly, the appareil amidonne, or starch bandage, which forms the subject of the present paper.
The principal advantages of this bandage, which-from the facility with which it is split, thus constituting, at will, a moveable and immoveable apparatus-has been termed also by its inventor, the appareil amovo-inamovible, are, 1st, that of effectually preventing any motion between the fractured extremities of the bones; this is evidently of the utmost importance in the treatment of all solutions of continuity in the osseous tissue, as, unless coaptation be maintained, not only will irritation and inflammation be excited, and the pain and suffering of the patient greatly prolonged, but also the formation of the callus considerably retarded, if not entirely prevented; for children and infants, also, whose restless nature is a source of considerable anxiety to the surgeon, in consequence of the difficulty thereby experienced in maintaining perfect immobility of the fractured bones, the starch bandage is an invaluable apparatus. All others, independent of their total inability to maintain perfect coaptation, become, in cases of fracture of the lower extremity, constantly saturated by the alvine and urinary excretions. They therefore require to be frequently changed, in order to prevent the irritation, excoriation, and fotor, which would otherwise be occasioned. But this frequent changing must evidently cause considerable pain to the patient, as well as greatly retard the formation of the callus, by allowing the fractured ends of the bones to rub against each other. Thus, it will be perceived, that by remedying one evil the surgeon creates another. In the delirium occurring in cases of compound fracture from extensive laceration of the soft parts, injury of the nerrous filaments, \&c., no apparatus will so effectually prevent the fragments producing that disturbance unon which the delirium in many cases depends. It forms, with the fractured limb, a whole, which cannot move without the concourse of its constituent parts. Hence the impossibility of any partial movement taking place, or the occurrence of any displacement of the broken bones, the whole limb being obliged to move in the direction of any impulse given. "Neither can there be free motion in any articulation; for supposing a bone was solicited to move on another, it will be prevented from doing so by two diametrically opposite surfaces of the bandage; hence it is easy to conclude that the muscular contractions themselves will be unable to produce any change in the relation between the fractured surfaces, since, on the one hand, the contraction, requiring a certain lateral space for the development of the fibres, can but imperfectly take place, and on the other, although it might be freely effected, the displacement would be rendered impossible by the contentive means."* The compression, also, which this bandage exercises, considerably suppresses the suppuration occurring in compound fractures', which, from its frequently being very excessive, greatly reduces the strength of the patient, and consequently protracts his recovery. It likewise secludes the purulent matter from the free contact of air, and thus renders its absorption much less dangerous. In gun-shot fractures of the articulating extremities of bones, in which, when amputation has not been immediately performed, a cure can only be obtained by ankylosis, the starch bandage affords an excellent means for securing this desirable termination, by preventing all motion of the joint; 2 ndly, that of adapting itself, when properly applied, to all elevations and depressions, consequently it exercises an equal degree of pressure on all parts, and is therefore not liable to produce congestion or mortification; on the contrary, it acts antiphlogistically by giving tone to the ressels, relieving the inflammation, and by preventing any unneccssary afflux of the fiuids towards the fractured limb, allows this to receive only sufficient for the repair of the solution of continuity; 3rdly, that it does not become deranged, but remains in the same position as when applied; 4 thly, that it admits of progression, and enables the patient to be removed to any part without danger; thus, the adult patient who has been accustomed to a life of activity, is no longer under the painful necessity of remaining in bed during the formation and consolidation of the callus, there to become exhausted and cachectic by a long-continued decubitus, and a prey to his bitter reflections, but is able to change his position, get up, and even walk about on crutches, and by this means recruit his strength, relieve his mind, and facilitate and hasten his recovery. Those severe and distressing cases of ulceration and gangrene which are so commonly met with, especially in old people, and which are consequent on remaining long in the recumbent posture, are of verv rare occurrence, if not entirely unknown to those who employ the "6 appareil amoreinamovibie;" 5thly, that of the materials of which it is composed being economical and easily procured; 6thly, that it is equally applicable to all kinds of fractures; Thly, that it 
admits of the limb being placed either in a state of flexion or extension, of pronation or supination, or of abduction or adduction; 8thly, that it is more easily removed, and more speedily applied, than any other apparatus; 9thly, that from the facility with which it may be divided, it forms, as its name implies, a moveable and immovable appareil at will. These advantages are certainly not trivial, and when they are considered together with the success with which it has been attended in the hands of several distinguished surgeons, in the treatment, not only of both simple and compound fractures, but also of dislocations, ruptured tendons, caries, and other affections of the joints, \&c. \&c., it is a matter of surprise that this bandage has not been more favourably received and more generally adopted by the profession in this country.

On the mode of application.-The necessary requisites are one of Scultetus's bandages or a common roller, two or three old linen bandages, of convenient length and breadth for the fractured limb, some pasteboard, of sufficient stiffness and firmness, from which splints are to be torn rather than cut of the proper size, in order that their edges may be so levelled off as to lie evenly on the limb, instead of being sharp and angular, and thus produce an injurious pressure on certain parts, and some fresh well-made starch. These things having been previously prepared, the surgeon immediately proceeds to reduce the fracture. When this is accomplished, and while the bones are being maintained in apposition by an assistant, a bandage is to be applied first round the toes,-for instance, supposing it to be a fracture of the leg, taking care, however, to keep their extremities free, as an index to the condition of the remainder of the limb. Those parts which from their prominence are likely to receive too great a degree of pressure, and, by this means, become inflamed and gangrenous, such as the ankles, the tendon of the tibialis anticus, the spine and tuberosities of the tibia, the head of the fibula, and the condyles of the femur, are then to be guarded with wadding or amadon, previous to the application of the first roller. This is then to be passed round the foot and leg, as high as the knee, or to a short distance above it, according to the situation of the fracture, and afterwards slightly starched for the purpose of fixing its edges; if more be applied, it will penetrate through to the internal surface of the roller, which will, in consequence, be rendered harsh and irritating to the skin. The posterior splint, from which a semicircular piece has been torn to allow of a space for the heel, having been softened in water, starched, and padded, is now to be applied and secured with the second roller, which must be well starched by means of a brush, or the palm of the hand. The lateral splints, prepared as the posterior one, are next applied, and over them the third bandage, which should receive a good coating of starch. If preferred, the lateral splints may be applied at the same time as the posterior one. However, I think more firmness is obtained by applying them as I have stated. If more solidity should be required, a fourth, and even a fifth bandage may be apnlied. It is advisable, previous to the application of the bandages, the first, however, excepted, to dip their extremities in the starch; by this means the edges become fixed as the bandage is unrolled. The end of the last bandage should also be folded in and placed in a conspicuons place. In cases of compound fractures, the apparatus must be so applied as to allow a free exit to the secreted fluids; thus, the edges of the rollers must either be turned back from the solutions of continuity, or holes cut in those situations corresponding to them, and the splints either notched or perforated. A communication can then, if necessary, be established between two openings, and a free discharge promoted. The wounds can also, by this contrivance, be dressed according to circumstances. Metal splints are sometimes requisite to give support to the fractured limb when the apparatus becomes softened by an abundant suppuration. Extension and counter-extension should be kept up until the bandage is perfectly dry. An old shape, resulting from a previously treated fracture, is an excellent addition to secure perfect coaptation during its desiccation, which may, in some cases, be promoted by hot bricks, bottles of hot wrater, bags of heated sand, or by exposing the limb to a fire or the sun's rays. In fractures of the lower extremity in children, the bandage should be covered over, when dry, with white of egg or some lind of varnish, or enveloped in a piece of oiled skin, in order to prevent its being soiled and softened by the excretions.

The period at which the bandage should be applied has been and still is a point of much controversy. Professor Suetin is in favour of its immediate application, whether tumefaction be present or not, and states that, instead of its being followed by any ill effects, it lessens the tranmatic in- flammation by diminishing the affiux of blood, promotes the absorption of that already effused, and favours the circulation by its compression, which should be gentle and equal.

Others argue that if the bandage is applied where there is much tumefaction, and before this has arrived at its height, either strangulation will be the consequence, or else the swelling will decrease and leave a vacuum between the surface of the member and the bandage, the result of which would be a want of proper support to the fractured bones. These are certainly objections, but objections of little weight. It is true, strangulation would be occasioned if the swelling should increase after the application of the bandage, but this would not be the case provided the apparatus were properly applied. I believe the following remark of $M$. Velpean to be perfectly just and founded on clinical observation-that " if there is no tumefaction, the bandage will prevent its recurrence; and if there is, and the pressure be well made, it will disappear." Whenever the swelling is considerable, I should recommend the first roller to be wetted in simple or Goulardwater previous to its being applied. This would tend to reduce the tumefaction; but should such not be the case, space would however be given for its increase by the expansion of the bandage in drying. It is true, also, that the bandage no longer affords the necessary support to the fractured limb when an empty space becomes formed between it and the latter, in consequence of the subsidence of the swelling. But this will be of but short duration, as it is sufficient, when the vacuum is but trifling, to soften it with water, then mould it to the shape of the fractured member, and finally to secure it by a starched roller; or if the vacuum is considerable, to split up the bandage with the scissors which Mr. Seutin has invented for that purpose, and remove a slip, if necessary, of the requisite width, and then bring it together again with a starched roller. The section of the apparatus is of the utmost importance: it enables the surgeon to make a careful examination of the limb, to remedy any improper pressure or defect, and to ascertain the position of the fractured bones. It should always be done on the following day or the day after. It causes no pain or displacement, and may be repeated as often as required without any danger of retarding the formation of the callus, as the posterior surface of the bandage gives the necessary support. It is a good plan, when applying the "bandage amidonne," to place a piece of tape in the situation where the section will have to be made, so as to serve as a guide to the scissors.

Langham-place, Feb. 1846.

\section{ON SARCOMATOUS TUMOURS}

(HYPERTROPHX)

AFFECTING THE MALE, AND SOMETIMES THE FEMALE ORGANS OF GENERATION.

BY F. HARINGTON BRETT, M.D.,

FELLOW OF THE ROYAI COLLEGE OF SURGEONS, LATE SURGEON TO THE GOVERNOR-GENERAL'S BODY GUARD, AND EYE INFIRAARY, BENGAL PRESIDENCY.

Some interest has been excited in two cases of this description, now in the wards of St. George's Hospital, one in a male, and the other in a female. A wider range of experience in the East, where these affections are allowed to acquire an enor. mous size, has permitted oriental practitioners to decide upon the true nature of their pathology, and to introduce an improved method of operating. There is still a degree of confusion in the nomenclature ${ }^{*}$ and classification of the disease in Europe, some confounding it with the "leprous elephantiasis," (a totally different complaint.) Surgeons in Europe are likewise still in error as to the method of operating. Important parts are sacrificed which ought to be preserved, and have been so repeatedly under the most skilful hands; and the best mode of finding a covering to the genitals, when

\section{* ANCIENT SYNONYMES. \\ Latin .... Elephantiasis, phlegmasia Malabarica, buenomia indica, hyper- sarcosis ulcerosa pedum. \\ Arabic .. Jielisla da-aol-feal $1, \mathrm{~J}$-dawali, as it affects the legs, or the other parts of the body.}

Persian .. lulis feal pa.

French .. Lépre tuberculeuse éléphantine.

Most or all of which names are confounded with leprosy by the various writers on these discases. 